\title{
A Climate Smartness Index (CSI) Based on Greenhouse Gas Intensity and Water Productivity: Application to Irrigated Rice
}

\author{
Laura N. Arenas-Calle ${ }^{1 *}$, Stephen Whitfield ${ }^{2}$ and Andrew J. Challinor ${ }^{1}$ \\ ${ }^{1}$ Institute Climate and Atmospheric Science, University of Leeds, Leeds, United Kingdom, ${ }^{2}$ School of Earth and \\ Environment, Sustainability Research Institute, University of Leeds, Leeds, United Kingdom
}

Efforts to increase agricultural productivity, adapt to climate change, and reduce the carbon footprint of agriculture are reflected in a growing interest in climate-smart agriculture (CSA). Specific indicators of productivity, adaptation and mitigation are commonly used in support of claims about the climate smartness of practices. However, it is rare that these three objectives can be optimized simultaneously by any one strategy.

OPEN ACCESS

Edited by:

Ngonidzashe Chirinda,

International Center for Tropical Agriculture (CIAT), Colombia

Reviewed by:

Birthe Katharina Paul, International Center for Tropical Agriculture, Kenya Niveta Jain,

Indian Agricultural Research Institute (ICAR), India

*Correspondence:

Laura N. Arenas-Calle eelnac@leeds.ac.uk

Specialty section: This article was submitted to Climate-Smart Food Systems, a section of the journal Frontiers in Sustainable Food Systems

Received: 25 March 2019 Accepted: 28 October 2019 Published: 15 November 2019

Citation:

Arenas-Calle LN, Whitfield S and Challinor AJ (2019) A Climate

Smartness Index (CSI) Based on Greenhouse Gas Intensity and Water Productivity: Application

to Irrigated Rice.

Front. Sustain. Food Syst. 3:105. doi: 10.3389/fsufs.2019.00105
In evaluating the relative climate smartness of different agricultural practices, plans and policies, there is a need for metrics that can simultaneously represent all three objectives and therefore be used in comparing strategies that have different benefits and trade-offs across this triad of objectives. In this context, a method for developing a Climate Smartness Index (CSI) is presented. The process of developing the index follows four steps: (1) defining system specific climate smartness; (2) selecting relevant indicators; (3) normalizing against reference values from a systematic literature review; and (4) aggregating and weighting. The CSI presented here has been developed for application in a systematic review of rice irrigation strategies and it combines normalized water productivity (WP) and greenhouse gas intensity (GHGI) The CSI was developed for application to data from published field experiments that assessed the impact of water management practices in irrigated rice, focusing on practices heralded as climate-smart strategies, such as Alternate Wetting and Drying (AWD). The analysis shows that the CSI can provide a consistent judgment of the treatments based on the evidence of water efficiency and reduced GHGI reported in such studies. Using a measurable and replicable index supports the aim of generating a reliable quantification of the climate smartness of agricultural practices. The same four step process can be used to build metrics for a broad range of CSA practice, policy and planning.

Keywords: climate-smart agriculture, climate smartness index, rice, AWD, water management

\section{INTRODUCTION}

Climate-Smart Agriculture (CSA) has been heralded as the basis of transformative changes toward sustainability. As a response to climate challenges, CSA founded on mitigation, adaptation and productivity pillars has been presented as an approach in agriculture aimed at simultaneously achieving three goals: increasing productivity, adapting to climate change, and reducing the GHG emissions (Lipper et al., 2014). To be meaningful, these generic CSA objectives need to be translated 
into specific properties of agricultural systems according to the relevant spatial and temporal scales and agro-climatic contexts of those systems (Rosenstock et al., 2016).

In many agricultural systems, it would not be possible to optimize for all three of these broad objectives simultaneously (Suckall et al., 2015; Notenbaert et al., 2017). The complex compatibilities and trade-offs between mitigation, adaptation and productivity objectives have contributed to ambiguities in how the CSA concept is interpreted in agricultural policy and planning (Thornton et al., 2018). It is not clear, for example, whether a strategy that optimizes yield is more or less climate smart than one that optimizes mitigation, or one that opts for a compromise across both. It is also important to recognize that "climate smartness", is a relative concept, and this is part of the reason for its ambiguity (Neufeldt et al., 2013).

The way we define and measure climate smartness should depend on the comparative question that is being asked. We may which to ask whether one agricultural practice is more or less climate smart than another in a given context or set of conditions, or we may which to ask whether it is more climate smart to adopt a give practice in context $\mathrm{A}$ vs. context $\mathrm{B}$ (with these contextual differences being delineated spatially or temporally or both). We may also ask whether you get a larger benefit from switching from one practice to another in context $\mathrm{A}$ or context $\mathrm{B}$. In all of these cases, we might adjust our choice of indicators and what we take as reference values, to reflect the contexts/practices against which we are comparing.

Although the productivity objective of CSA is relatively unambiguous, adaptation and mitigation require some systemspecific interpretation (Wollenberg et al., 2016). Relevant aspects of mitigation include reducing direct emissions from agricultural inputs and machinery, reducing field level emissions related to the anaerobic decomposition of organic matter, or the longer term storage of carbon in soils, for example (Smith et al., 2008; GIZ, 2014). The significance of these diverse sources and sinks differs greatly by production system and agro-ecological condition. In the case of adaptation, objectives should be considered relative to predominant climatic risks in a given context and these may relate to varied combinations of water scarcity, precipitation and temperature extremes, flooding, frost and heat stress that might impact the crops development (Wall and Smit, 2005; FAO, 2017).

There is no single replicable measure of climate smartness that captures its three objectives simultaneously and systematically accounts for the trade-offs between them. However, frameworks for monitoring and measure the climate smart properties of agricultural systems are being increasingly developed and utilized Frameworks such as "targetCSA" designed by Brandt et al. (2017) and Climate-smart agriculture rapid appraisal (CSA-RA) designed by Mwongera et al. (2017) offer a means to quantitatively assessing suitability and priority indices for CSA practices at a regional scale in Africa. The CGIAR Research Program on Climate Change, Agriculture and Food Security (CCAFS) have outlined an approach to measuring climate smartness using expert judgment (World Bank, 2014). The impact of adopting a particular climate-smart practice on each CSA pillar is scored separately in a range from 0 ("has no impact") to 5 ("Very high"), and the average of these numbers forms the final score. Whilst the individual scores based on expert judgements have broad application and context-specificity, they are not easily reproducible for the purposes of comparative studies. Similarly, the World Bank uses a group of CSA indices-the CSA Technology Index (CSA-Tech Index) and CSA Results Index (CSA-Res Index). Such indices are used in monitoring the suitability, implementation and progress of agriculture projects and use a large list of indicators of mitigation, adaptation, and productivity, grouped in different categories that are scored based on a specific threshold set accordingly to projected scope of the projects (World Bank, 2016), and so have limited general applicability.

The methodological approaches [rural participatory methods, Principal component analysis (PCA) to select indicators, analytic hierarchy, and expert judgement approach among others] adopted in the design of these CSA assessment frameworks, and the range of indicators drawn on within them, are indicative of the complexity of measuring climate smartness, as well as the importance of the context for its interpretation. However, it should be mentioned that even with the methodological differences among CSA indices and the CSI, there is commonality in their structure. All are derived from some degree of theorization of what CSA is, the translation of these principles into effective proxies, and an approach to weighting and aggregating them This structure is widely used in the construction of composite indicators and explained in detail by Nardo et al. (2005), OECD (2008), Mazziotta and Pareto (2013) and Baptista (2014). For the purposes of planning, monitoring and evaluating CSA, it is important to enrich the pool of CSA metrics with indices and indicators that integrate several dimensions (biophysical, economic, social, and environmental) in different spatial and temporal scales. Such metrics can support the analysis and monitoring of either the performance or the suitability of agricultural practices, or help to identify the climate-smart potential of agricultural systems.

Drawing on guidelines for the development of composite indicators (OECD, 2008; Mazziotta and Pareto, 2013; Baptista, 2014), we present a four-step process that can be applied in developing replicable qualitative indicators of climate smartness for a given context or set of research questions. We illustrate the process by presenting an index constructed for application in the systematic review of rice irrigation systems. A variety of irrigation regimes, such as AWD, are heralded as climate smart technologies within these systems (Wassmann, 2010; FAO, 2013; Rosenstock et al., 2016). By replacing the continual flooding of paddy rice systems, with a carefully managed regime of applying irrigation water only when soil moisture dips below a given threshold, it is thought that water inputs can be reduced by up to $30 \%$, and land-based methane emissions (which are high under the anaerobic conditions that continual flooding creates) can be reduced by $48 \%$ (Richards and Sander, 2014). This GHG reduction is meaningful considering that irrigated rice, is responsible for $\sim 10 \%$ of global emissions in the agriculture sector (Smith et al., 2014). 


\section{MATERIALS AND METHODS}

\section{Design of Climate Smartness Index (CSI)}

To design a composite index that provides a measure of climate smartness, a four-step approach was followed, and applied in the design of a CSI for irrigated rice systems. First, a conceptual definition of climate smartness in irrigated rice systems was developed (section Step One: Defining Climate Smartness in Irrigated Rice System). Second, a set of indicators to represent the critical climate smart trade-offs in these systems were selected (section Step Two: Indicators of Climate Smartness in Irrigated Rice). Third, these indicators were normalized by reference values (section Step Three: Normalization and Selection of Literature-Derived Reference GHGI and WP Values). Finally, the normalized indicators were weighted and aggregated (section Step Four: Weighting and Aggregation).

\section{Step One: Defining Climate Smartness in Irrigated Rice System}

Among the climate events that affect the rice crop (floods, heat stress, salinity, and droughts), water scarcity-related risks have become a substantial constraint for rice production (Pandey et al., 2007; Serraj et al., 2011; Tivet and Boulakia, 2017; Zhang et al., 2018; Kim et al., 2019). Several studies reported economic losses in rice crop by drought in north and north-eastern of China (Lin et al., 2013; Sekhar, 2018) and South Asia and southeast Asia (Pandey et al., 2007; Li et al., 2015; Prasanna, 2018), in addition to projected yield losses in some temperate and tropical regions within the next 50 years under "no adaptation" scenarios (Challinor et al., 2014). Added to the concern about water availability in drought-prone regions, GHG emissions from rice also represent a remarkable issue. Rice crop contributes $\sim 9-$ $11 \%$ to annual total non- $\mathrm{CO}_{2}$ emissions by agriculture (Smith et al., 2014). The major source of those contributions come from methane production under anaerobic conditions in flooded fields (Bouman et al., 2007; Suryavanshi et al., 2013).

Both, methane emissions and rice yields are highly sensitive to soil water content (Van Den Pol-van Dasselaar et al., 1998; Bouman et al., 2007; Singh et al., 2017) thus, water management becomes an important aspect of rice production and GHG mitigation (Meijide et al., 2017; Yang et al., 2017). Reductions in soil water content (either by climate events or reduction of irrigation frequency) contribute to reducing the $\mathrm{CH}_{4}$ production in the soil (Jiao et al., 2006; Haque et al., 2016). However, the relationship between soil water and GHG emissions is not strictly linear since other factors like temperature, $\mathrm{pH}$ and carbon inputs may constrain or promote the conditions for GHG production (Gaihre et al., 2016; Han et al., 2016). Furthermore, during soil drainage periods, a trade-off between $\mathrm{CH}_{4}$ and $\mathrm{N}_{2} \mathrm{O}$ could take place. The nitrous oxide produced by nitrification/denitrification process, could offset the potential mitigation of $\mathrm{CH}_{4}$ during soil draining and re-wetting events, or even increase the carbon footprint since the GWP of $\mathrm{N}_{2} \mathrm{O}$ is 9.5 times higher than $\mathrm{CH}_{4}$ (Johnson-Beebout et al., 2009; Kudo et al., 2014; Liu et al., 2016).

For its part, water reduction may also affect rice yield. Water stress promoted by reduction of soil water moisture can potentially reduce the productivity of the crop by affecting processes like tillering, panicle formation, flowering initiation, grain filling among others (Ookawa et al., 2000; Hayashi et al., 2006; Bouman et al., 2007). To avoid yield losses, continuous flooding conditions are traditionally implemented by the farmers since yield and total water input (TWI) has a positive correlation. However, this relationship has a limit. Beyond an attainable yield, the use of extra inputs will not necessarily lead to an increment in yield and, by the contrary, would reduce water productivity (Wichelns, 2002).

In water constrained conditions, the relationships between GHG emissions and yield and between water inputs and yield are key determinants of the climate smartness of an irrigation strategy. However, it may not be possible to optimize both of these relationships simultaneously, either because of the low capacity of the system to respond to the interventions (e.g., Sandy soils have high infiltration rates and thus water retention strategies are hardly successful) or by cross-effect processes (e.g., crop residue incorporation are beneficial for productivity but might increase GHG emissions by organic matter decomposition processes As such it is the trade-off between GHG emissions/yield and water inputs/yield, a measure of climate smartness that must account for the potential trade-offs between these.

\section{Step Two: Indicators of Climate Smartness in Irrigated Rice}

To represent the trade-off between water use/yield and /GHG emissions/yield, we constructed an index comprised of water productivity based on irrigation and rainfall (WP) and Greenhouse Gas Intensity (GHGI). Both WP and GHG are listed as performance indicators in the Performance indicators for sustainable rice cultivation published by Sustainable Rice platform (SRP, 2019), The Climate-Smart Agriculture indicators published by the World Bank (World Bank, 2016) and, the Climate-Smart Agriculture Sourcebook (FAO, 2013).

$\mathrm{WP}$ is defined as the ratio between rice yield ( $\mathrm{kg}$ grain/ha) and the TWI from irrigation and rainfall, expressed as $\mathrm{m}^{3}$ (Equation 1).

$$
P\left(\mathrm{~kg} \text { grain } / \mathrm{m}^{3}\right)=\frac{\text { yield }(\mathrm{kg} \text { grain } / \mathrm{ha})}{T W I_{(\text {irrigation }+ \text { rainfall })}\left(\mathrm{m}^{3} / \mathrm{ha}\right)}
$$

For its part, GHGI (or also called Yield-scaled GWP) is defined as the ratio between the total field-based GHG emissions expressed as Global Warming potential (GWP, $\mathrm{kg} \mathrm{CO}_{2}$-eq /ha /season) per yield rice, expressed as kg grain/ha grain (Equation 2).

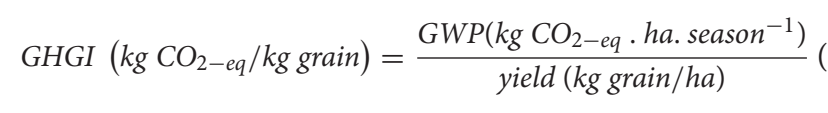

\section{Step Three: Normalization and Selection of Literature-Derived Reference GHGI and WP Values}

To transform the indicators into dimensionless and comparable values, GHGI and WP were normalized using the min-max normalization method (OECD, 2008; Mazziotta and Pareto, 2013). This normalization re-scales these indicator values from 
0 to 1 , giving them an easily associated "more is better" or "less is better" attribute, and thus facilitating the interpretation of each indicators' contribution in the CSI (Pollesch and Dale, 2016). This normalization method, has been used previously in environmental indices like the pollution index and composite environmental impact index (Khanna, 2000; Sabiha et al., 2016) as well as sustainability indices like City Development Index (CDI), Human Developed Index (HDI) among others (Böhringer and Jochem, 2007; Gómez-Limón and Sanchez-Fernandez, 2010; Muthuprakash and Damani, 2019). As a method it has benefits both in terms of the simplicity of its calculation and the scope it offers for adapting the CSI to the context in which it is being applied. When using the CSI in a comparative analysis, it is straightforward to select reference values that are representative of the fixed conditions that are being compared, and to normalize the index against these.

For this type of normalization, minimum and maximum thresholds of WP and GHGI were required. For application in a systematic literature review of the climate smartness of rice irrigation, we derived normalization values from our reviewed literature. The search was made in ScienceDirect and Google Scholar databases using the following keywords searched in the article titles: "rice" and "water productivity"; "rice" and "GWP"; "rice and "GHGI"; "rice" and "agronomic management"; and "water management"; "rice" and "yield"; "rice and "water use."

Data from field experiments that reported all or any of the following variables: yield, TWI, GHG emissions $\left(\mathrm{CH}_{4}\right.$ and $\mathrm{N}_{2} \mathrm{O}$ ), GWP (Global Warming potential, expressed in $\mathrm{CO}_{2}$-eq ha ${ }^{-1}$ season ${ }^{-1}$ ), and Water Productivity based on irrigation and rainfall, were selected. For this search, the studies that reported the use of the closed chamber technique as GHG sampling method were selected, Eddy Covariance and incubations techniques were excluded due to methodological and fluxes calculation differences. GHGI and WP values from 80 studies published between 2005 and 2019 were consulted (see Supplementary Materials 1 and 2). A total of 499 GHGI values were collected from the studies consulted (Figure 1A). The average for GHGI was $1.24-\mathrm{kg} \mathrm{CO} 2-\mathrm{eq} / \mathrm{kg}$ grain, and minimum and maximum values were 0.01 and $7.65 \mathrm{~kg} \mathrm{CO}$-eq $/ \mathrm{kg}$ grain, respectively. In the case of WP, references values were obtained from a dataset compiled from 33 studies that resulted in 381 WP values (Figure 1B). The average WP was $0.79 \mathrm{~kg}$ grain $/ \mathrm{m}^{3}$ and the minimum and maximum values 0.12 and $3.69 \mathrm{~kg}$ grain $/ \mathrm{m}^{3}$, respectively.

Thus, these reference values were used a GHGI and WP used to calculate the index. The indicators were normalized on a scale of 0 to 1 as shown in Equations (3) and (4):

$$
\begin{array}{r}
G H G I_{(N)}=\frac{G H G I_{o b s}-G H G I_{\min }}{G H G I_{\max }-G H G I_{\min }} \\
W P_{(N)}=\frac{W P_{o b s}-W P_{\min }}{W P_{\max }-W P_{\min }}
\end{array}
$$

GHGImin ( $=0.01-\mathrm{kg} \mathrm{CO}$-eq $/ \mathrm{kg}$ grain $)$ and WP min $(=0.1 \mathrm{~kg}$ grain $/ \mathrm{m}^{3}$ ) are the minimum reference values of both variables and, GHGImax $\left(=7.8 \mathrm{~kg} \quad \mathrm{CO}_{2}\right.$-eq $/ \mathrm{kg}$ grain $)$ and WPmax $\left(=3.7 \mathrm{~kg}\right.$ grain $\left./ \mathrm{m}^{3}\right)$ are the maximum values.
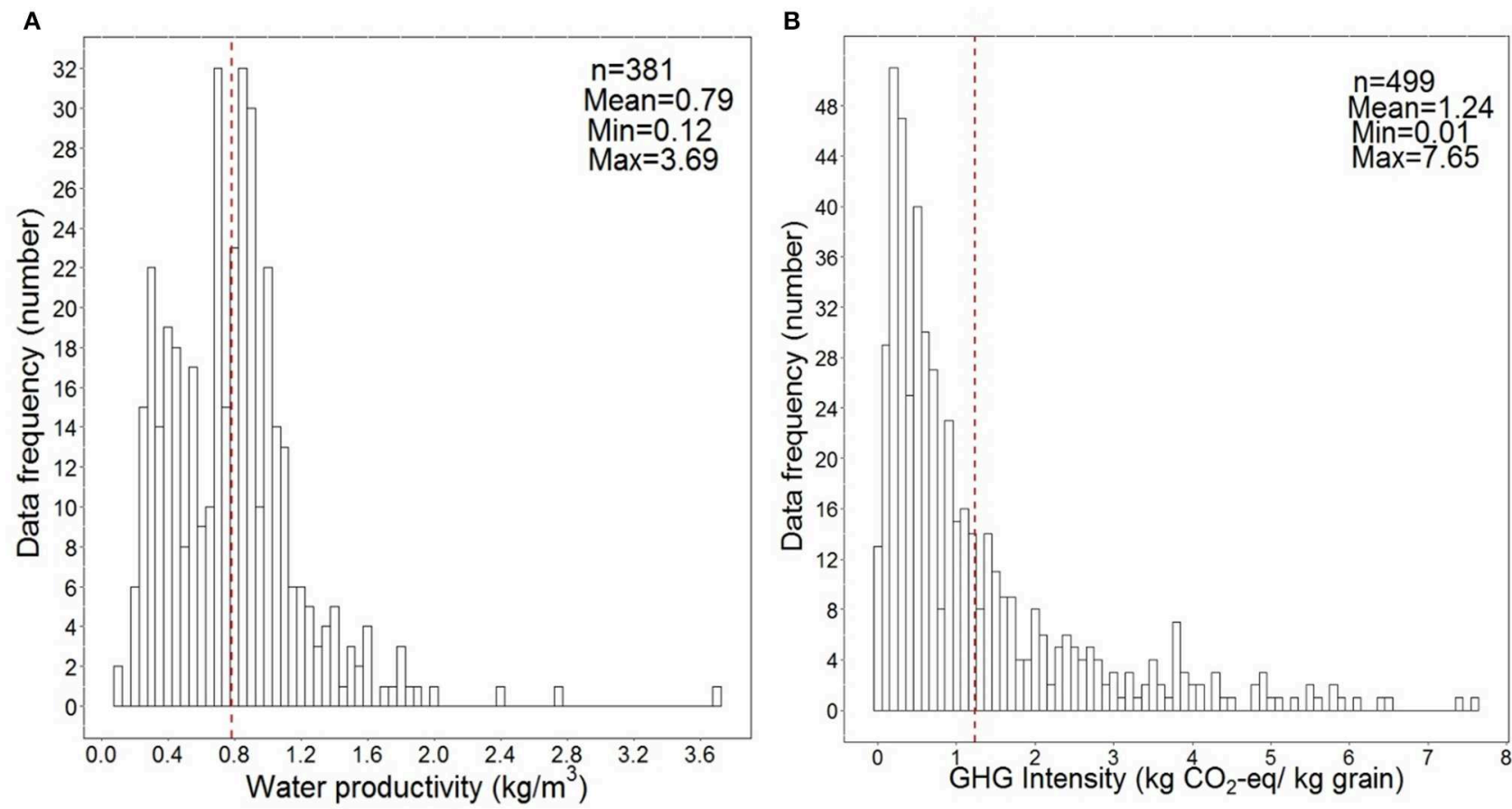

FIGURE 1 | Frequency distribution of Greenhouse Gas intensity ( $\mathrm{kg} \mathrm{CO}_{2}$-eq/kg grain, A) and Water Productivity (kg/m³ dotted line indicated the average of the dataset. 
The values found in the literature are intended to represent a relevant reference point based on representative agronomic practices of irrigation, $\mathrm{N}$ management, tillage, residue incorporation in relevant rice producer regions. These should be adapted for the systems and questions to which a CSI is being applied. It is important to recognize that these reference values are, themselves, not absolute. New studies may report higher or lower $\mathrm{max} / \mathrm{min}$ values in the future. Given that reference values come from different contexts to which the CSI is being applied (as the case described here), care should be taken not to interpret them as attainable goals. The climate smartness results derived from the index should be interpreted as relative scores that are bounded by ref. values, rather than absolute scores, within which there is a specific climate-smart threshold.

\section{Step Four: Weighting and Aggregation}

Improvements in individual indicators may be interpreted as climate smart where these represent a particular priority within a given system. For instance a reduction in GHGI contribution may be more of a priority in rice growing environments (i.e., those where there are particular policy incentives to reduce agricultural emissions) than in others. In our case, normalized GHGI and WP (that take values from 0 to 1 ) were assigned an equal weighting, this type of weighting is commonly used when indicators are considered equally important and there are no statistical grounds for choosing a different weighting (Gan et al., 2017). The equal weighting assignment also corresponds with the CSA principle of the trade-offs between productivity with mitigation or adaptation are equally considered climate-smart since the prioritization of one CSA pillar in specific should be evidenced in the index instead of being induced by the weighting.

To aggregate the normalized indicators, the additive aggregation method was used. This aggregation method provides a compensatory effect on both indicators (Munda and Nardo, 2005). This compensation represents the trade-off between the amount of GHG produced by a unit of grain yield and the amount of water used and allow the possibility of offsetting a disadvantage of an increasing of GHGI by a sufficiently large increasing of WP and vice versa.

The normalized GHGI value was subtracted from normalized WP to represents the compensatory effect of a GHGI increment over the overall climate smartness in a certain rice system. On the contrary, WP contributes positively to the index, representing the climate smartness associated with efficient use of water. Thus, the climate smartness score can progressively increase when WP increases and GHGI decreases. Conversely, the climate smartness could be diminished by an increment in GHGI simultaneously with a decreasing WP (Equation 5).

$$
C S I=W P_{(N)}-G H G I_{(N)}
$$

Given this configuration, the scale of CSI ranges from -1 to 1. A high CSI score (close to 1) indicates a situation of high water-efficient rice production and low greenhouse gas emissions relative to literature-derived reference values. Conversely, low CSI scores represent conditions where the rice crop has a high GHG footprint and low water efficiency.

\section{Application of the Climate Smartness Index (CSI)}

From the database compiled in step three of the material and methods section, studies with available data to calculate the index-those representing controlled experiments comparing continuous flooding with other irrigation management strategies and in which yield, GHG and water input data were availablewere selected. This resulted in a subset of 16 studies, which are summarized in Table 1. A paired comparisons analysis between AWD and continuous flooding treatments was carried out, using the CSI.

Alternative water management strategies to continuous flooding (CF), take a variety of forms. In furrow irrigation, water saturated soil conditions were maintained along crop cycle while Sprinkler Irrigation used a pivot irrigation system to keep optimal soil water content. For its part, in Controlled Irrigation (CI), the irrigations events are determined by the water requirements at different growth stages (Yang et al., 2014). Finally, AWD promotes the alternation of dry and wet periods, where the dry periods are maintained until the soil water content in the first $20 \mathrm{~cm}$ (rhizosphere zone) drops to pre-defined soil water content thresholds. Those thresholds can be conservative-"safe-AWD" (soil water potential $>20 \mathrm{kPa}$ ); or more drastic water stress conditions (soil water potential $<-20 \mathrm{kPa}$ ).

\section{RESULTS}

Across the 16 studies, the range of CSI values for AWD treatments ranged from -0.3 to 0.72 , while the range for $\mathrm{CF}$ was -0.62 to 0.44 . Other water management strategies like FI, SI, CF-30\%, CF-70\% have a closer CSI range with CF treatments $(-0.67$ to 0.5$)$. The broad CSI range in the water treatments might be the result of differences in the agro-ecological context of the studies. Due to the lack of representability, a limited geographical analysis of CSI was possible. From the 16 studies, 6 are from China, with a mean CSI ranged from 0.33 to 0.08 , that was considerably higher compared with the mean CSI of the other Asian countries represented in the sample like Vietnam, India, Thailand, Indonesia, and Java (mean CSI $=-0.27$ to 0.20 ).

At study level, the highest CSI was scored by the treatments assessed by Linquist et al. (2015) (mean CSI $=0.43 ; n=12$ ). This average CSI is the result of a high mean WP $\left(1.71 \mathrm{~kg} / \mathrm{m}^{3}\right)$, compared with the mean WP among the studies used to set the references max. and min. WP values $\left(0.79 \mathrm{~kg} / \mathrm{m}^{3}\right)$, combined with a low GHGI (mean GHGI $=0.156 \mathrm{CO}_{2}-\mathrm{eq} / \mathrm{kg}$ grain); that was significantly lower than the average GHGI from the dataset of (1.24 kg CO 2 -eq/ kg grain). The lowest climate-smartness were evidenced in the treatments reported by Tran et al. (2017) $(-0.49$ to -0.11$)$ and Fangueiro et al. (2017) ( -0.67 to 0.23$)$.

Despite high CSI variability within similar water treatments, in all the studies the water management alternatives scored higher CSI than CF treatments (Figure 2). According to CSI calculated for the results reported by Yang et al. (2012), Controlled Irrigation (CI) treatment showed higher climate smartness compared with CF, similarly the results reported by Fangueiro et al. (2017), showed that Sprinkler irrigation (SI) 
TABLE 1 | Summary of selected studies used to validate the CSI.

\begin{tabular}{|c|c|c|c|c|c|c|}
\hline \multirow[t]{2}{*}{ References } & \multirow[b]{2}{*}{ Country } & \multicolumn{2}{|l|}{ Soil } & \multicolumn{3}{|c|}{ Agronomic management } \\
\hline & & Texture & $\mathrm{pH}$ & Planting method & Water management & Organic amendment \\
\hline Chu et al., 2015 & China & Sandy loam & - & $\mathrm{T}$ & CF-AWD & Straw \\
\hline Chidthaisong et al., 2017 & China & Clay & 4.8 & PB & CF-AWD & - \\
\hline Fangueiro et al., 2017 & Spain & Loam & - & DS & Sl-CF & - \\
\hline Jain et al., 2014 & India & Loam & 8 & TPR-SRI-MSRI & CF-SRI/AWD-MSRI/AWD & - \\
\hline Lagomarsino et al., 2016 & Italy & Silty clay loam & - & $\mathrm{DR}$ & CF-AWD & - \\
\hline Liang et al., 2017 & China & - & 6 & $\mathrm{~T}$ & CF-AWD & - \\
\hline Linquist et al., 2015 & United States & Silt Loam & 5.60 & DR & CF-AWD & - \\
\hline Setyanto et al., 2018 & Java & Loam & - & $\mathrm{T}$ & CF-AWD & - \\
\hline Sibayan et al., 2017 & Philippines & Clay & 7 & $\mathrm{~T}$ & CF-AWD & Organic amendment \\
\hline Sun et al., 2016 & Philippines & - & 7.6 & $\mathrm{~T}$ & CF & - \\
\hline Tarlera et al., 2016 & Uruguay & Loamy clay & $5.5-6.3$ & DS & CF-AWD & - \\
\hline Tirol-Padre et al., 2018 & Vietnam Indonesia Thailand & Loam-Clay Loam & $3.5-5.8$ & DS-T-PB & CF & - \\
\hline Tran et al., 2017 & Vietnam & Loam & 4.18 & DS & CF-AWD & - \\
\hline Wang et al., 2018 & China & Sandy Loam & - & DS & CF-FI-AWD & Wheat straw \\
\hline Yang et al., 2012 & China & - & - & $\mathrm{T}$ & $\mathrm{Cl}-\mathrm{CF}$ & - \\
\hline
\end{tabular}

Studies selected from the dataset in Step Three: Normalization and Selection of Literature-Derived Reference GHGI and WP. T, Transplanted; DS, Direct seeding; DR, Dry-seeding; PB,

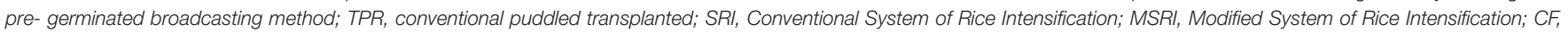
Continuous Flooding; AWD, Alternate Wetting and Drying; Fl, Furrow Irrigation; Cl, Controlled Irrigation; SI, sprinkler irrigation.

scored higher CSI than CF, although that scored the lowest CSI among the studies (mean CSI $=-0.19, n=15$ ). The CSI also showed differences when was calculated for different seasons. Tirol-Padre et al. (2018), reported results for wet and dry growing seasons in Southeast Asia, where dry season scored higher CSI (mean CSI $=-0.04$ ) than the same CF treatment during the wet season $(\mathrm{CSI}=-0.19)$.

\section{CSI of Contrasting Water Managements: CF vs. AWD}

CSI scores were calculated and compared along paired experimental studies of water saving strategies-categorized as either AWD and Continuous flooding (CF). The overall climate smartness associated with water management practices can be evidenced using the CSI metric. Seventeen paired comparison between CF and AWD were analyzed. The results showed that AWD scored higher than CF in all cases. Those differences could be associated with changes in Water productivity (indicated by the vertical arrows in Figure 3), GHGI (indicated by horizontal arrows in Figure 3) or both (arrows with some slope degree). The implementation of AWD in all cases, improved the climate smartness independently of the site. The magnitude of the changes generated by the AWD implementation can be evidenced by the CSI differences between paired comparisons.

The greater differences between paired comparisons were up to 0.5 in treatments reported by Linquist et al. (2015), due to the difference of WP that was double in AWD. These treatments presented a relative low GHGI (below to the average) that did not change between treatments. Paired comparisons with GHGI upper the average and WP below to average, showed CSI differences between 0.12 and 0.19 , mainly associated with the reduction on GHGI. The CSI differences provide a quantitative measure of the adoption impact, however, might not inform about what originated those differences.

The study that showed the largest CSI difference between treatments was (Linquist et al., 2015), which showed a CSI difference of 0.26 between CF (mean CSI $=0.22$ ) and AWD/40 (mean CSI $=0.560$ ). It is recalled that this AWD/40 treatment represents the most severe $\mathrm{AWD}$ option, in terms of water reduction, that Linquist et al. (2015) assessed for. AWD/40 was the treatment with the lowest TWIs and with a yield penalty of $-13 \%$. However, the AWD/40 treatment showed an increase of $63 \%$ in irrigation water-use efficiency and a reduction of $\mathrm{CH}_{4}$ emissions by $86 \%$, in comparison with continuous flooding treatments (Linquist et al., 2015).

In contrast to the CSI results of Linquist et al. (2015), the CSI differences between AWD and CF treatments carried out by (Tarlera et al., 2016), showed a closer difference. Although AWD held higher CSI $(\mathrm{CSI}=0.17)$ comparing with $\mathrm{CF}(\mathrm{CSI}=0.12)$ this slight difference was the result of a reduction in GWP rather than water savings benefits. It should be noted that even with a difference of $46 \%$ in GWP between CF and AWD, the trade-off between water-saving (12\%) and yield losses (-11\%), under AWD, did not represent a gain in water productivity, and consequently did not improve the CSI significantly.

Apart from CSI differences between AWD and CF, seasonal differences were evident. In the case of experiments reported by Tran et al. (2017), the winter-spring season trial achieved higher CSI (mean CSI $=0.24$ ) for both AWD and CF treatments compared with the CSI scores in the summer-autumn season trial (mean CSI $=-0.14$ ). Those differences resulted from high GWP during the summer-autumn season. According to the authors, this might be due to differences in the air temperature added to the short fallow period between both cropping seasons. 


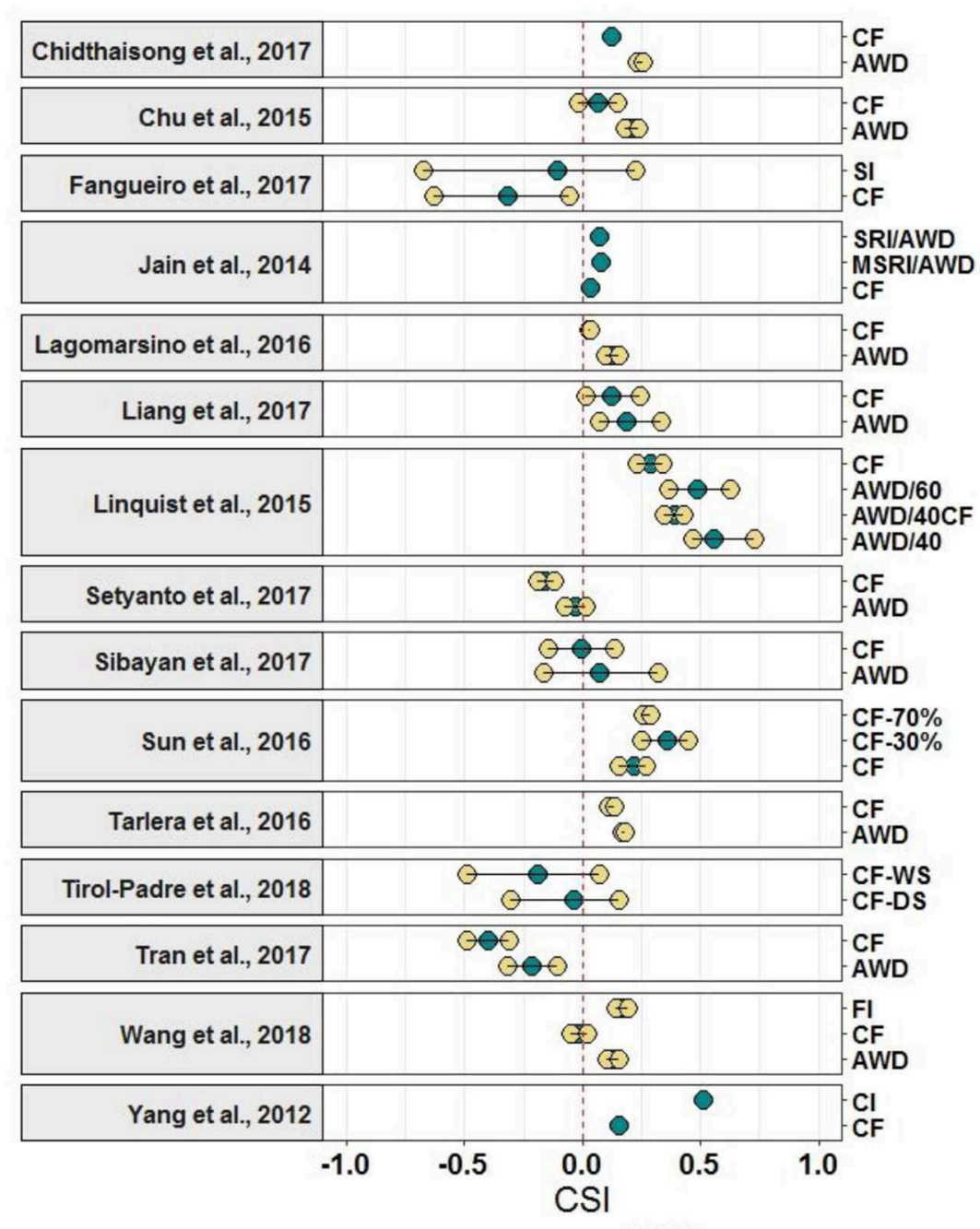

FIGURE 2 | CSI scores of the selected studies. Yellow circles represent max and min CSI values in the studies and green circles represent the CSI average. The labels in the right axis indicate the water management treatments that were assessed. CF, Continuous Flooding; CF-70\%, 70\% of normal irrigation; CF-30\%, 30\% of normal irrigation; AWD, Alternate Wetting and Drying; AWD/60, AWD treatments were irrigated until soil moisture reached $60 \%$ of saturated volumetric water-measured at $5 \mathrm{~cm}$ depth when the plots were re-flooded; AWD/40, AWD treatments were irrigated until soil moisture reached $40 \%$ of saturated volumetric water-measured at $5 \mathrm{~cm}$ depth when the plots were re-flooded; AWD/40CF, AWD treatments were irrigated until soil moisture reached $40 \%$ of saturated volumetric water-measured at $5 \mathrm{~cm}$ depth when the plots were re-flooded, up until the plants reached the reproductive growth stage; after which a flood was maintained up until the field was drained for harvest; Cl, Controlled Irrigation; SI, Sprinkler irrigation; CF-WS, Continuous Flooding during Wet Season; CF-DS, Continuous Flooding during Dry Season; Fl, Furrow Irrigation; SRI/AWD and MSRI/AWD, Irrigation was given on twice a week to keep soil just moist $(3.5 \mathrm{~cm})$.

The fallow left in the field during summer-autumn season translates into carbon sources for anaerobic bacteria populations, responsible for methane production. For its part, results reported by Liang et al. (2017) also showed seasonal differences in CSI. In the early season experiments, the CSI between AWD and CF was 0.04 . Meanwhile, in the late rice season, it was 0.09 . This difference between seasons resulted from a reduction of TWI during late rice and a yield increment of $13 \%$.

The CSI also changed between AWD and CF treatments when these were combined with other agronomic managements. Chu et al. (2015) reported that AWD and CF treatments with straw incorporation scored lower CSI $(\mathrm{CF}+\mathrm{S}=-0.01$,
$\mathrm{AWD}+\mathrm{S}=0.19)$ than the same water management without the straw incorporation (CF-S $=0.14$, AWD-S $=0.23$ ). In both AWD+ Straw and AWD-Straw, the water saving was similar (19-20\%), however, the emissions increased 2.53 times when the straw was incorporated under CF condition, resulted in a negative CSI. This rise of GHG emissions is caused by the anaerobic litter breakdown under CF, which produces methane (Zschornack et al., 2011; Das and Adhya, 2014). The same increment of $\mathrm{CH}_{4}$ emissions was evidenced in AWD+Straw, however, the dry periods promoted along the crop cycle allowed for greater soil aeration, constraining the anaerobic respiration. 


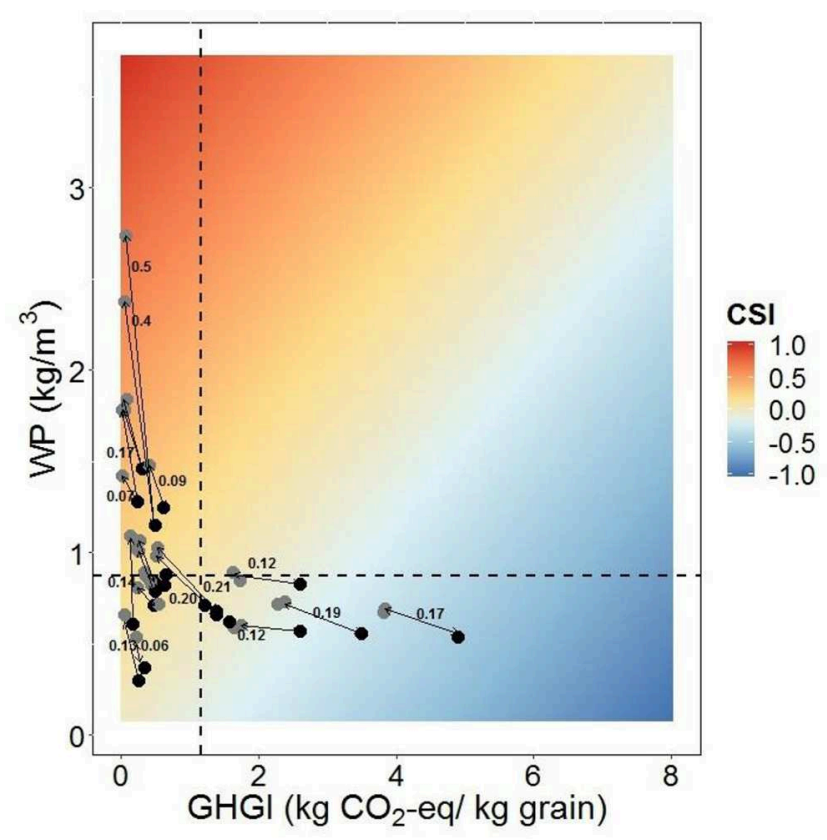

FIGURE 3 | Scatterplots of the relationship between Global Warming Potential (GHGl) and Water Productivity (WP) plotted over a heat map indicating CSI values. Gray circles represent AWD treatments and black circles Continuous flooding treatments. The arrows link paired treatments from the same studies and the numbers close to the arrows indicate the CSI difference between them. The vertical dotted line represents the mean GHGl of studies in the dataset and horizontal dotted line, the mean WP.

\section{DISCUSSION}

\section{How Climate-Smart Are the Water Management Alternatives in Rice? Putting CSI in Practice}

The way that indicators have been combined within the CSI is done so on the understanding that the critical factors affecting climate smartness in irrigated rice systems are the relationships between water input and yield and between GHG emissions and yield. Furthermore, it I recognized that these two relationships may not be optimized simultaneously and it is therefore important to consider the potential for trade-offs between them. Indeed, this is illustrated in examples of AWD trials, in which water savings and emissions reductions outweigh yield costs, when compared with continuous flooding practices (e.g., Linquist et al., 2015; Tarlera et al., 2016).

The CSI analysis presented here suggests universal improvements in the climate smartness of water management alternatives when compared with continuous flood irrigation. However, the performance of water management systems is also influenced by the agro-ecological conditions, climate change and social dynamics where they are implemented (De Silva et al., 2007; Sikka et al., 2018). This contextualized understanding of irrigation management is emerging within a growing body of experimental trials of these techniques. For instance, Dou et al. (2016) reported that clay soils favored water and nutrient retention more than sandy soils, resulting in higher tiller production and grain filling of cultivars. Similarly, Carrijo et al. (2017), in their meta-analysis of the impact of AWD on yield and water use, concluded that high Soil Organic Carbon (SOC) content, low bulk density and aggregate stability can result in better AWD performance.

Consequently, we cannot explain the climate smartness associated with AWD without considering suitability. Nelson et al. (2015) designed a methodology based on a water balance model to assess the suitability of AWD. The authors claimed that sites with a negative water balance will be more suitable than regions with a positive water balance, where the rainfall excess could lead to extra cost by drainage labor. This corresponds with the results of Sibayan et al. (2017), who reported a significant reduction of water inputs in $\mathrm{AWD}$, compared with $\mathrm{CF}$, during the dry season (> 50\%) compared with a $20 \%$ of reduction during wet season. As a consequence, AWD treatments under the dry season (CSI $=0.25$ to 0.31 ) resulted in a higher CSI score than AWD treatments during the wet season (CSI $=-0.11$ to -0.16 ).

The way that the CSI is aggregated allows an easy association between high WP-low GHGI with climate-smartness, and low WP-high GHGI, with low climate-smartness in irrigated rice systems. Consequently, a reduction of GHG emissions might not be considered climate-smart by itself if it is associated with significant yield penalties. In the same way, where improved WP is associated with increased GHG emission, this will not necessarily represent a climate-smart change. However, situations in which individual CSA pillar improve considerably with respect to others, or even at the expense of them, should be carefully considered, as CSA priorities may not be the same in all cases (Campbell et al., 2014; Lipper et al., 2014; Totin et al., 2018). Regarding the relative nature of CSA, it would be possible to alter the weighting of the components of the CSI, in order to offer a measure of climate-smartness representative of contextual priority indicators.

While the use of composite indices may result in a loss of information (Baptista, 2014; Pollesch and Dale, 2016), metrics like the CSI can help to reduce the ambiguities associated with the interpretation of CSA; responding to a concern over the consistency of claims about what is and is not climate smart (Rosenstock et al., 2016; Saj et al., 2017; Karlsson et al., 2018; Taylor, 2018). In this sense, both the methodological approach and CSI results, bring objectiveness to the communication of evidence related to climate-smartness in rice. Thus, under an agreed climate-smartness definition and a replicable quantification of this, subjective interpretations could be avoided. The "climate-smart" labeling of agricultural systems or agronomic strategies, based on biased interpretations of CSA indicators or the misconception of a mandatory "triple win" goal, are examples of that. In both cases, the CSI could offer a transparent measure of climate-smartness.

\section{Considerations About the Climate Smartness Index (CSI) Design}

Since its launch by the FAO in 2009, Climate Smart Agriculture has been reshaped and consolidated by an 
increasing pool of scientific evidence related with the impact of agronomic practices on CSA pillars and their suitability (Lipper and Zilberman, 2018). However, the contextdependent nature of CSA and the comprehensive range of cropping systems and environments where the agriculture is developing, add to the considerable challenge of quantitatively measuring and comparing the climate smartness of practices (Wollenberg et al., 2016; Torquebiau et al., 2018).

The approach to developing a CSI presented here, offers a means to quantitatively measuring and comparing the combined mitigation, adaptation and productivity properties of agricultural practices. The specific CSI presented is a suitable metric for contexts in which the primary climate-driven constraint, relates to water availability; and where there is concern over changing climate risks, such as drought, changing rainfall patterns or increasing temperatures and evaporation rates in the field. We have normalized this CSI for application in a systematic comparative review of rice irrigation management, by using reference values from this literature.

As explained by Dobbie and Dail (2013) and Mazziotta and Pareto (2013) indicator selection should be underpinned by a clear theoretical framework, explaining in this case what represents CSA in a given context. For the CSI proposed, the theoretical framework was focused on explaining the context in which the optimization of water use and the reduction of GHG could be considered climate-smart. For this, a waterscarcity climate risk context was given. This specification is important since rice is also threatened by other climate risks like sub-emergence, soil salinity and high temperatures (Mohanty et al., 2013), and thus the climate smartness meaning may change according to it.

Some studies, like Tivet and Boulakia (2017) in Vietnam, and Geetha Lakshmi et al. (2016) in India, have associated low GHG emissions and high water productivity with climate smartness. However, the conceptual framework present here, also recognizes the importance of the relationships between water use and yield and water use and GHG emissions, as well as the potential that these relationships may not be optimized simultaneously within a rice irrigation system (Wassmann, 2010; Saharawat et al., 2012; Xu et al., 2015; Yao et al., 2017). The CSI could offer an easy interpretation of the trade-offs between indicators instead of relying on them being analyzed separately.

Another key aspect of CSI design was the selection of indicators, which is considered an important step in the design of composite indices and should be selected according to their relevance, robustness, availability, accuracy, etc. (Mazziotta and Pareto, 2013; Reytar et al., 2014; Pollesch and Dale, 2016). The selection of WP and GHGI was based on a deductive approach (Wiréhn et al., 2015), over the theoretical understanding of the variables as indicators of mitigation and adaptation (FAO, 2013; World Bank, 2016; Devkota et al., 2019; SRP, 2019), and the trade-offs that they could represent. Although the deductive approach might be subjective, WP and GHGI have been recognized by Reytar et al. (2014) as a good proxy for environmentalrelated with water (Water productivity) and climate change (GHGI). The authors analyzed the indicators according to availability, accuracy, consistency, frequency and differentiation and concluded that WP and GHGI have high availability and are highly relevant for decision making as well as differentiating by countries or regions, however, its accuracy and consistency is medium.

The selection of the indicators also corresponds to the trade-off that they represent. Both indicators are expressed in terms of grain yield, representing the relation between the water inputs and GHG emissions involved in rice production. In this sense, an increment of WP would be given by either an increase in productivity or reduction of water inputs (Tuong and Bouman, 2003; Heydari, 2014). The water-saving is desirable, however, if this represents a significant yield penalty, are not desirable for farmers (Bouman and Tuong, 2001; Wu et al., 2017) and unsustainable in the medium and long term. Similarly, by using GHGI as an indicator of mitigation is also considering the mitigation associated with increasing yields that could avoid increases in emissions by rice area expansion (Adhya et al., 2014).

The CSI has been bounded using generic reference values of WP and GHGI, these values are used to create a finite set of possible values that the index could take, within realistic and reliable boundaries. Given the normalization method used (MinMax), the references min and max values selected from the literature and used to normalize the indicators are not necessarily constants into the CSI. This type of transformation is not stable since new data becomes available at some point and might be out the range of the references values (OECD, 2008). Such reference values can be changed at the light to discoveries, or be fitted according to a specific spatial or temporal baseline, or according to target and thresholds established in the frame of policies (Pollesch and Dale, 2016; Muthuprakash and Damani, 2019). The generic nature of the reference values used explains why we see, in some contexts, a relatively low sensitivity to irrigation strategy in the CSI. As climate-smart agriculture (CSA) is a relative concept the reference values could be set up based on clear-described targets or contextualized baseline conditions. For instance, the CSI compared between Asian countries showed a difference between China and the rest of Asian countries represent in the study. This gap is, in part, a result of the high yield traits of Chinese rice varieties and so it may be appropriate to use a different reference value when evaluating CSI within China, as opposed to within Asia as a whole, so that the CSI is more sensitive to differences in practice within this context.

\section{Application and Potential of the CSI Approach}

The methodological approach presented in this paper can be replicated for the design of metrics that support climate smartness assessments:

- Comparing the relative climate smartness of different practices in a given context, based on experimental site data.

- Comparing the climate smartness of a single practice across contexts (across space and time).

- Comparing the climate smartness of a contextualized practice to a hypothetical target or reference (which could be used for normalizing the index). 
- Comparing response ratios between contrasting treatments (i.e., AWD vs. CF) across different agroenvironmental contexts.

Consistently with the context-dependent nature of the CSA approach, the approach to developing a CSI set out here is designed to be flexible enough to be adapted to different cropping systems under several climate contexts, by the modification of the CSI indicators, reference values and aggregation options required. For instance, direct seasonal emissions may not represent the dominant source of emissions in all agricultural cropping systems, in these cases, the amount of sequestered carbon or indirect contributions (e.g., use of inorganic fertilizers, intensive tillage, post-harvesting residues management, among others), would represent more accurate proxies for mitigation. Similarly, adaptation objectives are context-specific, and associated with different primary climate risks (e.g., in rice systems there may be a primary concern with submergence, pests and diseases; heat stress, drought stress, and soil/water salinity).

The replicable and quantitative metric that a CSI represents within these applications, makes it potentially valuable in informing the targeting of agricultural support programs and development initiatives, and in helping to direct agronomic research agendas and evaluation methodologies, for which climate smartness is a central objective. However, it is important to highlight that there are some situations within which the CSI could be open to misinterpretation. It should avoid being interpreted as an absolute measure of the climate smartness of a practice (as opposed to a relative one) and nor should it be used to compare of contrasting agronomic management in different contexts (e.g., AWD in Asia vs. CF in Africa).

\section{CONCLUSIONS}

An approach to developing a climate smartness index is presented and then applied in a systematic review of irrigated rice systems. The process of developing the index follows four steps: (1) defining system specific climate smartness; (2) selecting relevant indicators; (3) normalizing against reference values; and (4) weighting and aggregating by additive methods. The CSI presented here offers a novel contribution to the

\section{REFERENCES}

Adhya, T. K., Linquist, B., Searchinger, T., Wassmann, R., and Yan, X. (2014). "Wetting and drying: reducing greenhouse gas emissions and saving water from rice production," in Working Paper, Installment 8 of Creating a Sustainable Food Future (Washington, DC: World Resources Institute). Available online at: http://www.wri.org/sites/default/files/wettingdrying-reducing-greenhouse-gas-emissionssaving-water-rice-production.pdf Baptista, S. R. (2014). Design and Use of Composite Indices in Assessment of Climate Change Vulnerability and Resilience. United States Agency International Development (USAID).

Böhringer, C., and Jochem, P. E. P. (2007). Measuring the immeasurable - A survey of sustainability indices. Ecol. Econ. 63, 1-8. doi: 10.1016/j.ecolecon.2007.03.008 growing body of literature on CSA by providing a single quantifiable metric of climate smartness. The approach is applied in comparative measures of the climate smartness of irrigation strategies in which the predominant mitigation concern relates to field level emissions, and the predominant adaptation actions aim for tackle the limitations in water availability. Future developments of this work may focus on the development of equivalent metrics for application in other agricultural systems and contexts, contributing to the building of a replicable and comparable evidence base for climate-smart agricultural practice and planning.

\section{DATA AVAILABILITY STATEMENT}

All datasets generated for this study are included in the article/Supplementary Material.

\section{AUTHOR CONTRIBUTIONS}

SW, AC, and LA-C contributed conception of the metric designed. LA-C organized the database, calculations, and wrote the first draft of the manuscript with support from SW and AC. All authors provided critical feedback and helped shape the research, analysis and manuscript.

\section{FUNDING}

This work was implemented as part of the CGIAR Research Program on Climate Change, Agriculture and Food Security (CCAFS), which is carried out with support from the CGIAR Trust Fund and through bilateral funding agreements. For details please visit https://ccafs.cgiar.org/donors. The views expressed in this document cannot be taken to reflect the official opinions of these organizations.

\section{SUPPLEMENTARY MATERIAL}

The Supplementary Material for this article can be found online at: https://www.frontiersin.org/articles/10.3389/fsufs. 2019.00105/full\#supplementary-material

Bouman, B. A. M., Lampayan, R. M., and Tuong, T. P. (2007). Water Management in Irrigated with Water Rice: Coping Scarcity. Los Baños: International Rice Research Institute.

Bouman, B. A. M., and Tuong, T. P. (2001). Field water management to save water and increase its productivity in irrigated lowland rice. Agric. Water Manage. 1615, 1-20. doi: 10.1016/S0378-3774(00)00128-1

Brandt, P., Kvakić, M., Butterbach-Bahl, K., and Rufino, M. C. (2017). How to target climate-smart agriculture? Concept and application of the consensusdriven decision support framework "targetCSA". Agric. Syst. 151, 234-245. doi: 10.1016/j.agsy.2015.12.011

Campbell, B. M., Thornton, P., Zougmoré, R., van Asten, P., and Lipper, L. (2014). Sustainable intensification: what is its role in climate smart agriculture? Curr. Opin. Environ. Sustain. 8, 39-43. doi: 10.1016/j.cosust.2014. 07.002 
Carrijo, D. R., Lundy, M. E., and Linquist, B. A. (2017). Rice yields and water use under alternate wetting and drying irrigation: a meta-analysis. Field Crops Res. 203, 173-180. doi: 10.1016/j.fcr.2016.12.002

Challinor, A. J., Watson, J., Lobell, D. B., Howden, S. M., Smith, D. R., and Chhetri, N. (2014). A meta-analysis of crop yield under climate change and adaptation. Nat. Clim. Change 4, 287-291. doi: 10.1038/nclimate2153

Chidthaisong, A., Cha-un, N., Rossopa, B., Buddaboon, C., Kunuthai, C., Sriphirom, P., et al. (2017). Evaluating the effects of alternate wetting and drying (AWD) on methane and nitrous oxide emissions from a paddy field in Thailand. Soil Sci. Plant Nutr. 64, 31-38. doi: 10.1080/00380768.2017.1399044

Chu, G., Wang, Z., Zhang, H., Liu, L., Yang, J., and Zhang, J. (2015). Alternate wetting and moderate drying increases rice yield and reduces methane emission in paddy field with wheat straw residue incorporation. Food Energy Secur. 4, 238-254. doi: $10.1002 /$ fes3.66

Das, S., and Adhya, T. K. (2014). Geoderma Effect of combine application of organic manure and inorganic fertilizer on methane and nitrous oxide emissions from a tropical flooded soil planted to rice. Geoderma 213, 185-192. doi: 10.1016/j.geoderma.2013.08.011

De Silva, C. S., Weatherhead, E. K., Knox, J. W., and Rodriguez-Diaz, J. A. (2007). Predicting the impacts of climate change-A case study of paddy irrigation water requirements in Sri Lanka. Agric. Water. Manage. 93, 19-29. doi: 10.1016/j.agwat.2007.06.003

Devkota, K. P., Pasuquin, E., Elmido-Mabilangan, A., Dikitanan, R., Singleton, G. R., Stuart, A. M., et al. (2019). Economic and environmental indicators of sustainable rice cultivation: a comparison across intensive irrigated rice cropping systems in six Asian countries. Ecol. Indic. 105, 199-214. doi: 10.1016/j.ecolind.2019.05.029

Dobbie, M. J., and Dail, D. (2013). Robustness and sensitivity of weighting and aggregation in constructing composite indices. Ecol. Indic. 29, 270-277. doi: 10.1016/j.ecolind.2012.12.025

Dou, F., Soriano, J., Tabien, R. E., and Chen, K. (2016). Soil texture and cultivar effects on rice (Oryza sativa, L.) grain yield, yield components and water productivity in three water regimes. PLOS ONE 11:0150549. doi: 10.1371/journal.pone.0150549

Fangueiro, D., Becerra, D., Albarrán, Á., Peña, D., Sanchez-Llerena, J., Rato-Nunes, J. M., et al. (2017). Effect of tillage and water management on ghg emissions from mediterranean rice growing ecosystems. Atmos. Environ. 150, 303-312. doi: 10.1016/j.atmosenv.2016.11.020

FAO (2013). Climate-Smart Agriculture Sourcebook. Sourcebook on Climate-Smart Agriculture, Forestry and Fisheries.

FAO (2017). Tracking Adaptation in Agricultural Sector. Rome: Climate Change Adaptation Indicators.

Gaihre, Y. K., Wassmann, R., Villegas-Pangga, G., Sanabria, J., Aquino, E., Sta. Cruz, P. C., et al. (2016). Effects of increased temperatures and rice straw incorporation on methane and nitrous oxide emissions in a greenhouse experiment with rice. Eur. J. Soil Sci. 67, 868-880. doi: 10.1111/ejss.12389

Gan, X., Fernandez, I. C., Guo, J., Wilson, M., Zhao, Y., Zhou, B., et al. (2017). When to use what: Methods for weighting and aggregating sustainability indicators. Ecol. Indic. 81, 491-502. doi: 10.1016/j.ecolind.2017.05.068

Geetha Lakshmi, V., Tesfai, M., Lakshmanan, A., Borrell, A., Nagothu, U. S., et al. (2016). "System of rice intensification: climate-smart rice cultivation system to mitigate climate change impacts in India," in Climate Change and Agricultural Development: Improving Resilience Through Climate Smart Agriculture, Agroecology and Conservation, ed U. S. Nagothu (Abingdon: Routledge), 232-258.

GIZ (2014). Assessing and Monitoring Climate Resilience from Theoretical Considerations to Practically Applicable Tools - A Discussion Paper.

Gómez-Limón, J. A., and Sanchez-Fernandez, G. (2010). Empirical evaluation of agricultural sustainability using composite indicators. Ecol. Econ. 69, 1062-1075. doi: 10.1016/j.ecolecon.2009.11.027

Han, X., Sun, X., Wang, C., Wu, M., Dong, D., Zhong, T., et al. (2016). Mitigating methane emission from paddy soil with rice-straw biochar amendment under projected climate change. Sci. Rep. 6, 1-10. doi: 10.1038/srep 24731

Haque, M. M., Biswas, J. C., Kim, S. Y., and Kim, P. J. (2016). Suppressing methane emission and global warming potential from rice fields through intermittent drainage and green biomass amendment. Soil Use Manage. 32, 72-79. doi: 10.1111/sum. 12229
Hayashi, S., Kamoshita, A., and Yamagishi, J. (2006).Effect of planting density on grain yield and water productivity of rice (Oryza sativa L.) grown in flooded and non-flooded fields in Japan. Plant Prod. Sci. 9, 298-311. doi: 10.1626/pps.9.298

Heydari, N. (2014). Water productivity in agriculture: Challenges in concepts, terms and values. Irrig. Drain. 63, 22-28. doi: 10.1002/ird.1816

Jain, N., Dubey, R., Dubey, D. S., Singh, J., Khanna, M., Pathak, H., et al. (2014). Mitigation of greenhouse gas emission with system of rice intensification in the Indo-Gangetic Plains. Paddy. Water. Environ. 12, 355-363. doi: 10.1007/s10333-013-0390-2

Jiao, Z., Hou, A., Shi, Y., Huang, G., Wang, Y., and Chen, X. (2006). Water management influencing methane and nitrous oxide emissions from rice field in relation to soil redox and microbial community. Commun. Soil Sci. Plan. 37, 1889-1903. doi: 10.1080/00103620600767124

Johnson-Beebout, S. E., Angeles, O. R., Alberto, M. C. R., and Buresh, R. J. (2009). Simultaneous minimization of nitrous oxide and methane emission from rice paddy soils is improbable due to redox potential changes with depth in a greenhouse experiment without plants. Geoderma 149, 45-53. doi: 10.1016/j.geoderma.2008.11.012

Karlsson, L., Naess, L. O., Nightingale, A., and Thompson, J. (2018). 'Triple wins' or 'triple faults'? Analysing the equity implications of policy discourses on climate-smart agriculture (CSA). J. Peasant Stud. 45, 150-174. doi: 10.1080/03066150.2017.1351433

Khanna, N. (2000). Measuring environmental quality: an index of pollution. Ecol. Econ. 35, 191-202. doi: 10.1016/S0921-8009(00)00197-X

Kim, W., Iizumi, T., and Nishimori, M. (2019). Global patterns of crop production losses associated with droughts from 1983 to 2009. J. Appl. Meteorol. Clim, 1233-1244. doi: 10.1175/JAMC-D-18-0174.1

Kudo, Y., Noborio, K., Shimoozono, N., and Kurihara, R. (2014). The effective water management practice for mitigating greenhouse gas emissions and maintaining rice yield in central Japan. Agric. Ecosyst. Environ. 186, 77-85. doi: 10.1016/j.agee.2014.01.015

Lagomarsino, A., Agnelli, A. E., Linquist, B., Adviento-Borbe, M. A., Agnelli, A., Gavina, G., et al. (2016). Alternate wetting and drying of rice reduced $\mathrm{CH}_{4}$ emissions but triggered $\mathrm{N}_{2} \mathrm{O}$ peaks in a clayey soil of central Italy. Pedosphere 26, 533-548. doi: 10.1016/S1002-0160(15)60063-7

Li, T., Angeles, O., Radanielson, A., Marcaida, M., and Manalo, E. (2015). Drought stress impacts of climate change on rainfed rice in South Asia. Clim. Change 133, 709-720. doi: 10.1007/s10584-015-1487-y

Liang, K., Zhong, X., Huang, N., Lampayan, R. M., Liu, Y., Pan, J., et al. (2017). Nitrogen losses and greenhouse gas emissions under different $\mathrm{N}$ and water management in a subtropical double-season rice cropping system. Sci. Tot. Environ. 609, 46-57. doi: 10.1016/j.scitotenv.2017.07.118

Lin, Y., Deng, X., and Jin, Q. (2013). Economic effects of drought on agriculture in North China. Int. J. Disaster Risk Sci. 4, 59-67. doi: 10.1007/s13753-013-0007-9

Linquist, B. A., Anders, M. M., Adviento-Borbe, M. A. A., Chaney, R. L., Nalley, L. L., da Rosa, E. F. F., et al. (2015). Reducing greenhouse gas emissions, water use, and grain arsenic levels in rice systems. Glob. Chang. Biol. 21, 407-417. doi: $10.1111 /$ gcb.12701

Lipper, L., Thornton, P., Campbell, B. M., Baedeker, T., Braimoh, A., Bwalya, M., et al. (2014). Climate-smart agriculture for food security. Nat. Clim. Change 4, 1068-1072. doi: 10.1038/nclimate2437

Lipper, L., and Zilberman, D. (2018). "A short history of the evolution of the climate smart agriculture approach and its links to climate change and sustainable agriculture debates," in Climate Smart Agriculture: Building Resilience to Climate Change, eds L. Lipper, N. McCarthy, D. Zilberman, S. Asfaw, and G. Branca (Cham: Springer International Publishing), 13-30. doi: 10.1007/978-3-319-61194-5_2

Liu, G., Yu, H., Zhang, G., Xu, H., Ma, J., and Rice, D. (2016). Combination of wet irrigation and nitrification inhibitor reduced nitrous oxide and methane emissions from a rice cropping system. Environ. Sci. Pollut. Res. 23, 17426-17436. doi: 10.1007/s11356-016-6936-2

Mazziotta, M., and Pareto, A. (2013). Methods for constructing composite indicators: one for all or all for one?, in Rivista Italiana Di Economia Demografia e Statistica, LXVII (Aprile-Giugno), 67-80. Retrieved from: http:// www.sieds.it/listing/RePEc/journl/2013LXVII_N2_10_Mazziotta_Pareto.pdf

Meijide, A., Gruening, C., Goded, I., Seufert, G., and Cescatti, A. (2017). Water management reduces greenhouse gas emissions in a Mediterranean rice paddy field. Agric. Ecosyst. Environ. 238, 168-178. doi: 10.1016/j.agee.2016.08.017 
Mohanty, S., Wassmann, R., Nelson, A., Moya, P., and Jagadish, S. V. K. (2013). "Rice and climate change: significance for food security and vulnerability," in IRRI Discussion Paper Series No. 49 (Los Baños: International Rice Research Institute).

Munda, G., and Nardo, M. (2005). Constructing Consistent Composite Indicators: The Issue of Weights. Ispra: Joint Research Centre.

Muthuprakash, K. M., and Damani, O. (2019). Design of farm assessment index (fai) for a holistic comparison of farming practices: case of organic and conventional farming systems from two Indian states. Agroecol. Sust. Food 43, 329-357. doi: 10.1080/21683565.2018.1547941

Mwongera, C., Shikuku, K. M., Twyman, J., Läderach, P., Ampaire, E., Van Asten, P., et al. (2017). Climate smart agriculture rapid appraisal (CSA-RA): A tool for prioritizing context-specific climate smart agriculture technologies. Agric. Syst. 151, 192-203. doi: 10.1016/j.agsy.2016.05.009

Nardo, M., Saisana, M., Tarantola, A., and Stefano, S. (2005). Tools for Composite Indicators Building. Retrieved from: http://collection.europarchive.org/ $\mathrm{dnb} / 20070702132253 / \mathrm{http} / / /$ farmweb.jrc.ec.europa.eu/ci/Document/EUR 21682 EN.pdf

Nelson, A., Wassmann, R., Sander, B. O., and Palao, L. K. (2015). Climatedetermined suitability of the water saving technology "alternate wetting and drying" in rice systems: a scalable methodology demonstrated for a province in the Philippines. PLoS ONE 10:e0145268. doi: 10.1371/journal.pone.0145268

Neufeldt, H. M., Jahn, B. M., Campbell, J. R., Beddington, F., DeClerck, A., De Pinto, J., et al. (2013). Beyond climate-smart agriculture: toward safe operating spaces for global food systems. Agric. Food Secur. 2:12. doi: $10.1186 / 2048-7010-2-12$

Notenbaert, A., Pfeifer, C., Silvestri, S., and Herrero, M. (2017). Targeting, outscaling and prioritising climate-smart interventions in agricultural systems: lessons from applying a generic framework to the livestock sector in subSaharan Africa. Agric. Syst. 151, 153-162. doi: 10.1016/j.agsy.2016.05.017

OECD (2008). Handbook on Constructing Composite Indicators: Methodology and User's Guide. Paris: OECD Publications.

Ookawa, T., Lu, J., and Hirasawa, T. (2000). The effects of irrigation regimes on the water use, dry matter production and physiological responses of paddy rice. Plant Soil 223, 207-216.

Pandey, S., Bhandari, H., Ding, S., and Prapertchob, P. (2007). Coping with drought in rice farming in Asia: insights from a cross-country comparative study. Agric. Econ. 31, 213-224. doi: 10.1111/j.1574-0862.2007.00246.x

Pollesch, N. L., and Dale, V. H. (2016). Normalization in sustainability assessment: methods and implications. Ecol. Econ. 130, 195-208. doi: 10.1016/j.ecolecon.2016.06.018

Prasanna, R. P. I. R. (2018). Economic Cost of Drought and Farmer's Adaptation Strategies: Evidence from Sri Lanka. SLJER, 61-79.

Reytar, K., Hanson, C., and Henninger, N. (2014). "Working paper: indicators of sustainable agriculture: a scoping analysis. Creating a Sustainable Food Future. Retrieved from: https://www.wri.org/sites/default/files/wrr installment_6_sustainable_agruiculture_indicators.pdf

Richards, M., and Sander, B. O. (2014). Alternate Wetting and Drying in Irrigated Rice: Implementation Guidance for Policymakers and Investors. Practice Brief on Climate-Smart Agriculture. Available online at: https://cgspace.cgiar.org/ bitstream/handle/10568/35402/info- note_CCAFS_AWD_final_A4.pdf)

Rosenstock, T. S., Lamanna, C., Chesterman, S., Bell, P., Arslan, A., Richards, M., et al. (2016). "The scientific basis of climate-smart agriculture: a systematic review protocol," Working Paper (Nairobi: ICRAF).

Sabiha, N. E., Salim, R., Rahman, S., and Rola-Rubzen, M. F. (2016). Measuring environmental sustainability in agriculture: a composite environmental impact index approach. J. Environ. Manage. 166, 84-93. doi: 10.1016/j.jenvman.2015.10.003

Saharawat, Y. S., Ladha, J. K., Pathak, H., Gathala, M., Chaudhary, N., and Jat, M. L. (2012). Simulation of resource-conserving technologies on productivity, income and greenhouse gas GHG emission in rice-wheat system. J. Soil Sci. Environ. Manage. 3, 9-22. doi: 10.1002/ghg.27

Saj, S., Torquebiau, E., Hainzelin, E., Pages, J., and Maraux, F. (2017). The way forward: an agroecological perspective for climate-smart agriculture. Agric. Ecosyst. Environ. 250, 20-24. doi: 10.1016/j.agee.2017.09.003

Sekhar, C. S. C. (2018). "Climate change and rice economy in Asia: implications for trade policy," in The State of Agricultural Commodity Markets (SOCO) (Rome, FAO), 62 .
Serraj, R., McNally, K. L., Slamet-Loedin, I., Kohli, A., Haefele, S. M., Atlin, G., et al. (2011). Drought resistance improvement in rice: an integrated genetic and resource management strategy. Plant Prod. Sci. 14, 1-14. doi: 10.1626/pps.14.1

Setyanto, P., Pramono, A., Adriany, T. A., Susilawati, H. L., Tokida, T., Padre, A. T., et al. (2018). Alternate wetting and drying reduces methane emission from a rice paddy in Central Java, Indonesia without yield loss. J. Soil Sci. Plant Nutr. 64, 23-30. doi: 10.1080/00380768.2017.1409600

Sibayan, E. B., Samoy-Pascual, K., Grospe, F. S., Casil, M. E. D., Tokida, T., Padre, A. T., et al. (2017). Effects of alternate wetting and drying technique on greenhouse gas emissions from irrigated rice paddy in Central Luzon, Philippines. J. Soil Sci. Plant Nutr. 00, 1-8. doi: 10.1080/00380768.2017.1401906

Sikka, A. K., Islam, A., and Rao, K. V. (2018). Climate-smart land and water management for sustainable agriculture. Irrig. Drain. 67, 72-81. doi: $10.1002 /$ ird.2162

Singh, B., Reddy, K. R., Redoña, E. D., and Walker, T. (2017). Screening of rice cultivars for morpho-physiological responses to early-season soil moisture stress. Rice Sci. 24, 322-335. doi: 10.1016/j.rsci.2017.10.001

Smith, P., Bustamante, M., Ahammad, H., Clark, H., Dong, H., E. A. Elsiddig., et al. (2014). "Agriculture, forestry and other land use (AFOLU)," in Climate Change 2014: Mitigation of Climate Change. Contribution of Working Group III to the Fifth Assessment Report of the Intergovernmental Panel on Climate Change, eds O. Edenhofer, R. Pichs-Madruga, Y. Sokona, E. Farahani, S. Kadner, K. Seyboth, A. Adler, I. Baum, S. Brunner, P. Eickemeier, B. Kriemann, J. Savolainen, S. Schlömer, C. von Stechow, T. Zwickel, and J. C. Minx (New York, NY; Cambridge: Cambridge University Press).

Smith, P., Martino, D., Cai, Z., Gwary, D., Janzen, H., Kumar, P., and Smith, J., et al. (2008). Greenhouse gas mitigation in agriculture. Philos. Trans. R. Soc. B. 363, 789-813. doi: $10.1098 /$ rstb.2007.2184

SRP (2019). The SRP Performance Indicators for Sustainable Rice Cultivation (Version 2.0). Sustainable Rice Platform. Bangkok. Available online at: http:// www.sustainablerice.org

Suckall, N., Stringer, L. C., and Tompkins, E. L. (2015). Presenting Triple-Wins? assessing projects that deliver adaptation, mitigation and development co-benefits in rural sub-saharan Africa. Ambio 44, 34-41. doi: 10.1007/s13280-014-0520-0

Sun, H., Zhou, S., Fu, Z., Chen, G., Zou, G., and Song, X. (2016). A two-year field measurement of methane and nitrous oxide fluxes from rice paddies under contrasting climate conditions. Sci. Rep. 6, 1-11. doi: 10.1038/srep28255

Suryavanshi, P., Singh, Y. V., Prasanna, R., Bhatia, A., and Shivay, Y. S. (2013). Pattern of methane emission and water productivity under different methods of rice crop establishment. Paddy Water Environ. 11, 321-329. doi: 10.1007/s10333-012-0323-5

Tarlera, S., Capurro, M. C., Irisarri, P., Scavino, A. F., Cantou, G., and Roel, A. (2016). Yield-scaled global warming potential of two irrigation management systems in a highly productive rice system. Sci. Agric. 73, 43-50. doi: 10.1590/0103-9016-2015-0050

Taylor, M. (2018). Climate-smart agriculture: what is it good for? J. Peasant Stud. 45, 89-107. doi: 10.1080/03066150.2017.1312355

Thornton, P. K., Whitbread, A., Baedeker, T., Cairns, J., Claessens, L., Baethgen, W., et al. (2018). A framework for priority-setting in climate smart agriculture research. Agric. Syst. 167, 161-175. doi: 10.1016/j.agsy.2018.09.009

Tirol-Padre, A., Minamikawa, K., Tokida, T., Wassmann, R., and Yagi, K. (2018). Site-specific feasibility of alternate wetting and drying as a greenhouse gas mitigation option in irrigated rice fields in Southeast Asia: a synthesis. J. Soil Sci. Plant Nutr. 64, 2-13. doi: 10.1080/00380768.2017.1409602

Tivet, F., and Boulakia, S. (2017). Climate Smart Rice Cropping systems in Vietnam. State of Knowledge and Prospects. Montpellier: CIRAD.

Torquebiau, E., Rosenzweig, C., Chatrchyan, A. M., Andrieu, N., and Khosla, R. (2018). Identifying Climate-smart agriculture research needs. Les Agri. Face Au Chang. Clim. 27:26001. doi: 10.1051/cagri/2018010

Totin, E., Segnon, A. C., Schut, M., Affognon, H., Zougmoré, R. B., Rosenstock, T., et al. (2018). Institutional perspectives of climate-smart agriculture: a systematic literature review. Sustainability 10:1990. doi: 10.3390/su100 61990

Tran, D. H., Hoang, T. N., Tokida, T., Tirol-Padre, A., and Minamikawa, K. (2017). Impacts of alternate wetting and drying on greenhouse gas emission from paddy field in Central Vietnam. J. Soil Sci. Plant. Nutr. 64, 14-22. doi: $10.1080 / 00380768.2017 .1409601$ 
Tuong, T. P., and Bouman, B. A. M. (2003). "Rice production in water scarce environments," in Proceedings of the Water Productivity Workshop, IWMI H032635 (International Water Management Institute), 12-14.

Van Den Pol-van Dasselaar, A., Van Beusichem, M. L., and Oenema, O. (1998). Effects of soil moisture content and temperature on methane uptake by grasslands on sandy soils. Plant Soil 204, 213-222. doi: 10.1023/A:1004371309361

Wall, E., and Smit, B. (2005). Climate change adaptation in light of sustainable agriculture. J. Sustain. Agric. 27, 113-123. doi: 10.1300/J064v27n01_07

Wang, Z., Gu, D., Beebout, S. S., Zhang, H., Liu, L., Yang, J., et al. (2018). Effect of irrigation regime on grain yield, water productivity, and methane emissions in dry direct-seeded rice grown in raised beds with wheat straw incorporation. Crop. Sci. 6, 495-508. doi: 10.1016/j.cj.2018.05.004

Wassmann, R. (ed.). (2010). “Advanced technologies of rice production for coping with climate change: 'no regret' options for adaptation and mitigation and their potential uptake," in Proceedings of the Workshop Advanced Technologies of Rice Production for Coping with Climate Change: 'No Regret' Options for Adaptation and Mitigation and their Potential Uptake held on 23-25 June 2010 in Los Baños, Philippines. IRRI Limited Proceedings No. 16. Los Baños: International Rice Research Institute, 81.

Wichelns, D. (2002). An economic perspective on the potential gains from improvements in irrigation water management. Agric. Water Manage 52, 233-248. doi: 10.1016/S0378-3774(01)00134-2

Wiréhn, L., Danielsson, Å., and Neset, T. S. S. (2015). Assessment of composite index methods for agricultural vulnerability to climate change. J. Environ. Manage 156, 70-80. doi: 10.1016/j.jenvman.2015.03.020

Wollenberg, E., Richards, M., Smith, P., Havlik, P., Obersteiner, M., and Tubiello, F. N. (2016). Reducing emissions from agriculture to meet the $2{ }^{\circ} \mathrm{C}$ target. Global Change Biol. 22, 3859-3864. doi: 10.1111/gcb.13340

World Bank (2016). Climate-Smart Agriculture Indicators. Climate-Smart Agriculture Indicators. doi: 10.1596/24947

World Bank, CIAT, and CATIE (2014). Climate-Smart Agriculture in Colombia. CSA Country Profiles for Latin America Series. Washington, DC: The World Bank Group.

Wu, X. H., Wang, W., Yin, C. M., Hou, H. J., Xie, K. J., and Xie, X. L. (2017). Water consumption, grain yield, and water productivity in response to field water management in double rice systems in China. PLoS ONE 12:e0189280. doi: 10.1371/journal.pone.0189280
Xu, Y., Ge, J., Tian, S., Li, S., Nguy-Robertson, A. L., Zhan, M., et al. (2015). Effects of water-saving irrigation practices and drought resistant rice variety on greenhouse gas emissions from a no-till paddy in the central lowlands of China. Sci. Tot. Environ. 505, 1043-1052. doi: 10.1016/j.scitotenv.2014. 10.073

Yang, J., Zhou, Q., and Zhang, J. (2017). Moderate wetting and drying increases rice yield and reduces water use, grain arsenic level, and methane emission. Crop J. 5, 151-158. doi: 10.1016/j.cj.2016.06.002

Yang, S., Peng, S., Hou, H., and Xu, J. (2014). Controlled irrigation and drainage of a rice paddy field reduced global warming potential of its gas emissions. Arch. Agron. Soil. Sci. 60, 151-161. doi: 10.1080/03650340.2013.7 72687

Yang, S., Peng, S., Xu, J., Luo, Y., and Li, D. (2012). Methane and nitrous oxide emissions from paddy field as affected by water-saving irrigation. Phys. Chem. Earth 53-54, 30-37. doi: 10.1016/j.pce.2011.08.020

Yao, Z., Zheng, X., Liu, C., Lin, S., Zuo, Q., and Butterbach-Bahl, K. (2017). Improving rice production sustainability by reducing water demand and greenhouse gas emissions with biodegradable films. Sci. Rep. 7, 1-10. doi: 10.1038/srep39855

Zhang, J., Zhang, S., Cheng, M., Jiang, H., Zhang, X., Peng, C., et al. (2018). Effect of drought on agronomic traits of rice and wheat: a meta-analysis. Int. J.Env. Res. Pub. Health 15:839. doi: 10.3390/ijerph15050839

Zschornack, T., Bayer, C., and Zanatta, J. A. (2011). Mitigation of methane and nitrous oxide emissions from flood-irrigated rice by no incorporation of winter crop residues into the soil (1). Rev. Bras. Ciência Do Solo 35, 623-634. doi: 10.1590/S0100-06832011000200031

Conflict of Interest: The authors declare that the research was conducted in the absence of any commercial or financial relationships that could be construed as a potential conflict of interest.

Copyright (c) 2019 Arenas-Calle, Whitfield and Challinor. This is an open-access article distributed under the terms of the Creative Commons Attribution License (CC $B Y)$. The use, distribution or reproduction in other forums is permitted, provided the original author(s) and the copyright owner(s) are credited and that the original publication in this journal is cited, in accordance with accepted academic practice. No use, distribution or reproduction is permitted which does not comply with these terms. 